\title{
EFEITO DO pH SOBRE O GRAU DE GERMINAÇÃO DE SEMENTES \\ DE Ocotea puberula (Lauraceae)
}

\section{pH EFFECTON THE DEGREE OF GERMINATION IN Ocotea puberula SEEDS (Lauraceae)}

\author{
SILVA, A. C.1,2; PORTELA, O.3,4; LORDEШO, A. L L2; \\ NOGUEIRA, A. C. ${ }^{4}$
}

\author{
${ }^{1}$ Aluno do Programa de Pós-graduação em Química - UFPR \\ 2 Departamento de Químic a - Universidade Federal do Paraná, CP 19081, CEP 81531-990, Curitiba - PR, Brasil. \\ ${ }^{3}$ Aluno do Programa de Pós-graduação em Ciências Florestais- UFPR \\ ${ }^{4}$ Departamento de Ciências Florestais - Universidade Federal do Paraná, CEP 80210-170, Cunitiba - PR, Brasil
}

\begin{abstract}
RESUMO
Estudos recentes utilizando sementes de Ocotea puberula consumidas porpássa ros têm mostrado que o grau de geminação, quando estas são regurgitadas pelos seus dispersores, é superior ao das não regurgitadas, sugenindo que a passagem das sementes pelo trato digestónio dos pássaros tenha fundamental importância no processo geminativo da espécie. Objetivando avaliar quantitativamente este parâmetro, foram realizados vários experimentos simulando a influência da concentração do ácido sulfúrico no grau de geminação de Ocotea puberula. Observou-se que a porcentagem de geminação das sementes testemunhas foi de $38 \%$ enquanto que, para as que passaram pelo tratamento ácido (em diferentes tempos) foi em tomo de $40 \%$, diferindo bastante dos $64 \%$ obtidos para as sementes regurgitadas pelas aves.
\end{abstract}

Palavras-chave: Ocotea puberula, Lauraceae, geminação.

\begin{abstract}
Recent studies have suggested that the degree of gemination in Oc otea puberula seed is greater when it is regurgitated by birds than the one that is not regurgitated. This fact suggests that the gemination process of Ocotea puberula seed is upregulated by the passage of the seeds through the dispersors' digestive tract, especially birds.

Thus, the aim of this study was to detect the influence of the gastric pHon the gemination deg ree of Ocotea puberula seeds.

Ourresults showed the percentage of gemination did not depend on the acid treatment, as follows: $38 \%$ for seeds not treated with acid (control group), $40 \%$ for those treated with acid in different concentrations and $64 \%$ for naturally regurgitated seeds.

Keywords: Oc otea pubenula, Lauraceae, gemination.
\end{abstract}

\section{INTRODUÇÃO}

Uma visão amplamente difundida atualmente é que o metabolismo secundánio estaria envolvido em interações da planta com outros organismos, havendo várias evidências do envolvimento dessas substâncias na atração de polinizadores (Wenny, 2000; Eby, 1998; et al. 1994), de agentes dispersores de frutos, na prevenção do crescimento de outras plantas, entre outros. Infelizmente, exemplos bem documentados são raros, e a importância desse papel como fator de seleção para a produção de metabólitos secundários permanece obscura (Waterman etal. 1989).

Os estudos de dispersão envolvendo a familia Laurac eae têm mostrado que entre os seus dispersores encontram-se macacos, roedores e pássaros, este último considerados seus principais dispersores pois alimentam-se preferencialmente de frutos de Lauraceae diferentemente de outros a nimais indicando que isso possa estar diretamente relacionado com o tipo de metabólitos secundánios presentes nos frutos. (Wheelwright et al. 1993).

Acredita-se que ospássaros selecionam sua alimentação ba seadosna sua percepção visual e dessa forma escolhem frutos de tamanhos adequadose de cores brilhantes como 
vermelho, preto, azul e roxo que encontram-se menosprotegidosna copas dasárvores. Osfrutosmaduros das Lauraceae diferentemente de outras espécies possuem frutos inodoros sugerindo que a escolha do fruto não parece estar relacionado a sina is químicos voláteis (Eby, 1998).

O mecanismo de dispersão dosfrutosocorre a pósa ingestão dosmesmosporpássaros e posterior regurgitação das sementes. Experimentos tem comprovado que se isso ocorrer a uma distânc ia superiora 20 m ou inferiora $50 \mathrm{~cm}$ de espéciesco-específicasa geminação não é efetiva. Isso ocome devido a um aumento da mortalidade das sementes causados pela ação de predadores (roedores, fungose bactérias) quando assementes se encontram no estágio inicial de crescimento (Wenny, 2000).

Na região Sul do Brasil, dentre os gêneros mais expressivos de La uraceae encontra-se o gênero Ocotea. Este gênero tem desperta do interesse dos fitoquímic os brasileiros, devido a sua ampla distribuição no temitónio nacional e o fato de suas espécies serem muito apreciadas no comércio madereiro, devido ao alto valor de sua madeira que é extremamente resistente ao ataque de organismos xilófagos (Rizzini et al. 1976). Contudo, muitas dessas espéc ies estão ameaçadas de extinção, pois além do desmatamento, as espécies de Ocotea não possuem constância na frutificação (Moura-Costa et al. 1994), fato este que dificulta a propagação da espécie.

Estudo envolvendo a utilização de frutos de Ocotea puberula por pássaros e sua influência na geminação das sementes realizadas em Irati-PR têm demonstrado que o grau de geminação das sementes regurgitadas é superiorà não regurgitadas, sugenindo que a passagem da semente pelo trato digestónio do dispersor seja fundamental para o processo geminativo da espécie (Nogueira et al. 2000), este fato nos motivou a testar a influência da concentração de ácido sulfúnico no grau de geminação da espécie Ocotea puberula.

\section{OBJ EIVO}

Simularascondições ácidas do trato digestónio dos pássaros, seus maiores dispersores, a fim de comprovara importância deste processo na quebra da possível dormência da semente, e postenior geminação desta.

\section{MATERIAL E MÉIODOS}

\subsection{Coleta do material vegetal}

Os frutos maduros de Ocotea puberula foram coletadas de cinco matrizes prédetermina das em duas reg iões distintas. Na região de Antonina - PR (Bioma Floresta Ombrófila Densa), osfrutosmaduros foram obtidosno peńodo de setembro/outubro de 2001, enquanto que na região do Colégio Florestal de Irati - PR (Bioma Floresta Ombrófila Mista), foram obtidos de dezembro/janeiro de 2001.

A coleta deste material foi realizada pelo aluno Osmael Portela sob onientação do professor Antonio Carlos Nogueira do Departamento de Ciências Floresta is da UFPR

As sementes foram coletadas de duas maneiras:

- utilizando telas do tipo sombrite, colocadas diretamente sob a projeção da copa das matrizes e desta forma possibilitando a coleta das sementes consumidas pelos pássaros; - coletando-se manualmente das árvores, isto é, frutos não consumidos. 
Osfrutos maduros depois de coletad os foram separados de suas respectivas sementes que posteniomente foram amazena das em local a propriado e mantidas sob refrigeração, evitando-se desta forma, que sofressem algum processo de decomposição, tomando-as inviáveis para os testes geminativos.

\subsection{Análise no processo geminativo das sementes}

Para serpossível simulara influência da concentração ácida no gra u de geminação, fezse um tratamento prévio com assementes não consumidaspelos pássaros. Esse se baseia em submeteressas sementesem uma solução de ácido sulfúrico a 30\%, em tempos diversos, para que desta forma, saiba-se quais são as melhores condições ácidas, para uma geminação ma isefetiva. Isso é possível comparando-se osresulta dosobtidos da geminação das sementes consumidase daquelas não consumidas, mas sem nenhum tratamento.

Após serem submetidas ao meio ácido, assementes foram lavadasem água corrente poraproximadamente 30 minutos, retirando-se assim qualquertraço ácido e a seguirforam submetidas à geminação em vermiculita.

Esse tratamento é feito em mais quatro replic atas, sendo que cada uma delas contém 50 sementes, para que não haja dúvida dos resultados no processo geminativo.

Procedeu-se a geminação, tanto das sementes consumidas como daquelas não consumidas (sem e com tratamento ácido), mantendo-se as mesmas condições nutric ionais e ambientais.

\section{RESULTADOS E DISCUSSÕES}

Os dados obtidos com as análises téc nicas foram:

Após um peńodo de aproximadamente 180 dias, observou-se que a porcentagem de geminação dassementesnão consumidas(sem tratamento ácido) foi de $38 \%$ enquanto que, nas consumidas foi de $64 \%$. Além disso, observou-se que as sementes não consumidas tratadas com o ácido, dependendo da sua permanência neste, tomam-se inviáveis para sua posteriorgeminação podendo o ácido ter danific ado células do embrião (gráfico 1).

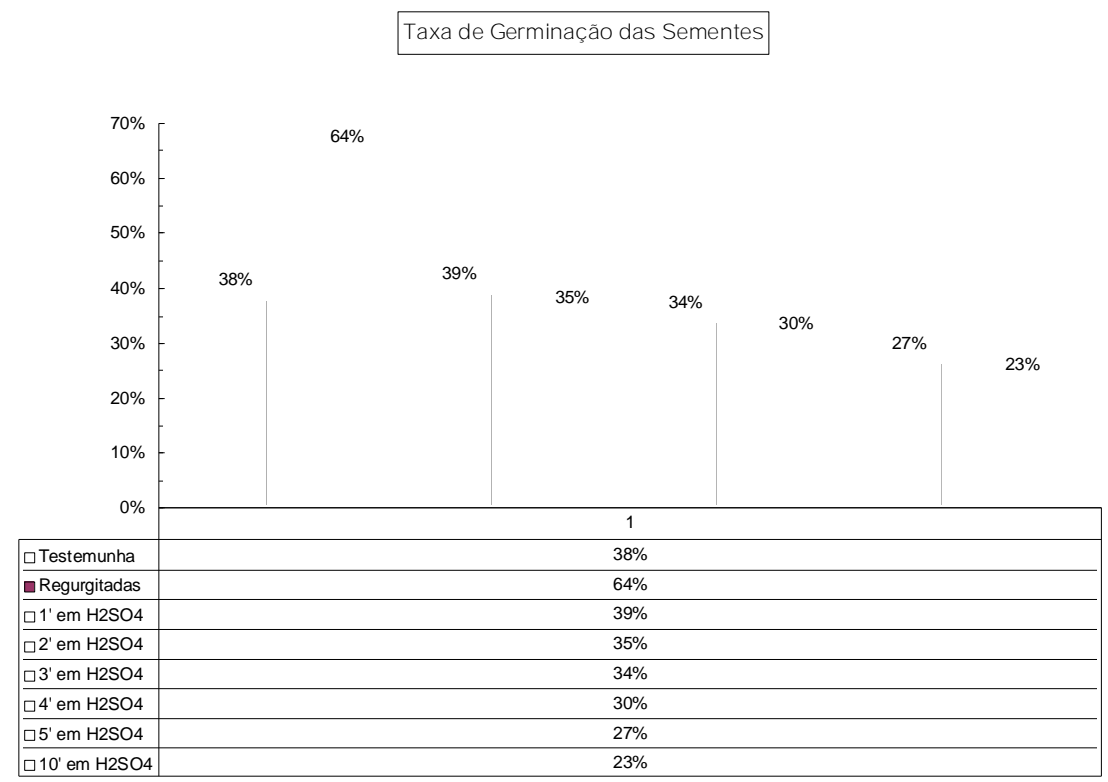

GRÁFICO 1: Taxa de geminação das sementes de Ocotea puberula procedentes de Antonina com e sem o tratamento de ácido sulfúnic o a $30 \%$. 


\section{CONCLUSÕES}

Os expenimentos rea lizadosmostraram que as sementes cujosfrutos foram consumidas pelos dispersores, encontram-se em uma condição mais viável para a geminação do que aquelas que não passam pelo trato digestónio dos mesmos. Este fato corrobora com os dados obtidos através da observação em campo. Os experimentos tentando simular o meio ácido adequado para a possível quebra de domência da sementes não foram efetivos já que os valores nas porcentagens de geminação foram na mesma faixa dos obtidos para as sementes não consumidas sem o tratamento ácido. Além disso os testes com ácido sulfúrico indicam que, quanto maior o tempo de permanência das sementes no ácido, menoré o rendimento no seu processo geminativo.

\section{REFERÊNCIAS}

1 ANGELY, J. Flora Ana lítica do Paraná. $1^{\text {a }}$ ed. São Paulo: Coleção Saint-Hilaire, 1965.

2 CIPOШNI, M. L; WAШACE- SENFT, D. E; WHIGHAM, D. F. J ournal of Ecology, v. 82; p. 62, 1994.

3 EBY, P. Australian J ournal of Ecology, v. 23; p. 443,1998.

4 GIBSON, J. P; WHEELWRIGHT, N. T. Oecologia, v. 103; p. 49, 1995.

5 GOTIUEB, O. R. Phytoc hemistry, v. 29, p. 1715, 1990.

6 HARBONE, J. Introduction to Ecological Biochemistry. 4a ed. Londres: Academic Press, 1998.

7 HEO, K; WERFF, H. Botanical J ournal of the Linnean Society, v. 70, n. 2; p. 295, 1998.

8 LORDEШO, A. L L Tese de Doutorado. São Paulo: IQ-USP, 1996.

9 LORDEШO, A. L L \& YOSHIDA, M. Phytoc hemistry, v. 46, p. 74, 1997.

1OMARQUES, M. O. M; GOMES, M. C. C. P; YOSHIDA, M. \& GOTILEB, O. R Phytoc hemistry, v. 31, p. $275,1992$.

11MAZIR, S. J; WHEELWRIGHT, N. Evolutionary Ecology, v. 7, p. 556, 1993.

12MOURA-COSTA, T. H. V. A. M; MANTEU, S. H. Plant Cell Tissue and Organ Culture, v. 35, p. 279, 1993.

13NOGUEIRA, A. C; PORTELA, O. IX EVINCI, 2000.

14RIZZNI, C. T. \& MORS, W. B. Botânica Econômica Brasileira. São Paulo: Editora EDUSP e EPU, 1976.

15WALTER, H. Vegetação e Zonas C limáticas. São Paulo: Ed. EPU, 1986.

16WENNY, D. G. Ecological Monographs, v. 70, n. 2; p. 33, 2000. 